Supplement of Atmos. Chem. Phys., 21, 8709-8734, 2021

https://doi.org/10.5194/acp-21-8709-2021-supplement

(C) Author(s) 2021. CC BY 4.0 License.

(c) (1)

Supplement of

\title{
Insights into seasonal variation of wet deposition over southeast Asia via precipitation adjustment from the findings of MICS-Asia III
}

Syuichi Itahashi et al.

Correspondence to: Syuichi Itahashi (isyuichi@criepi.denken.or.jp)

The copyright of individual parts of the supplement might differ from the article licence. 

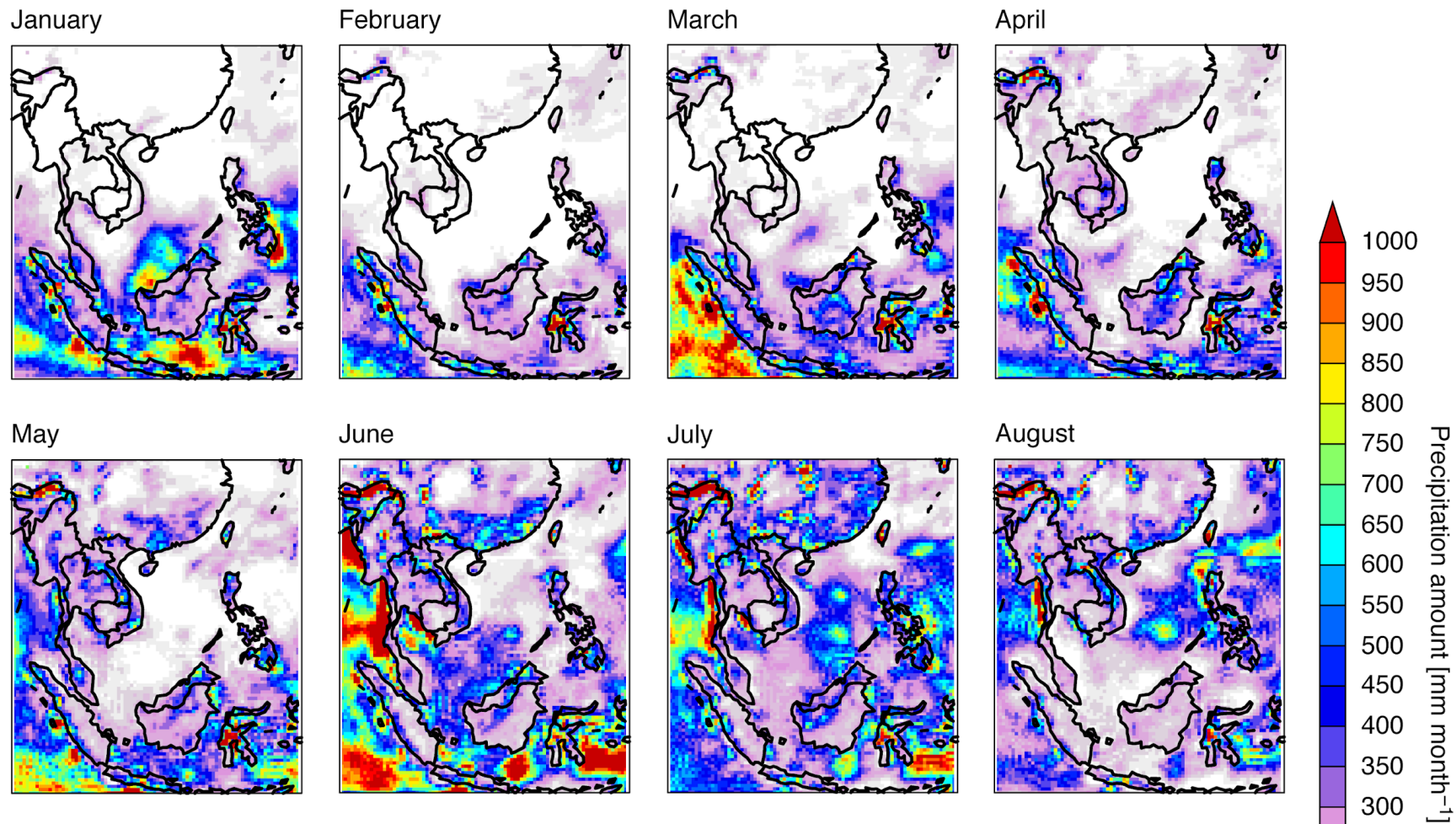

September

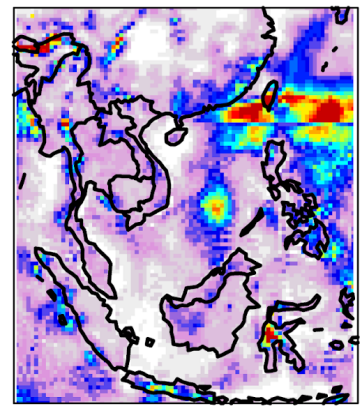

October

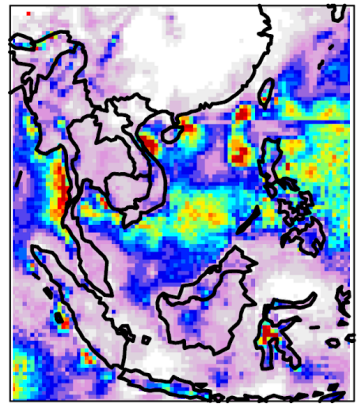

November

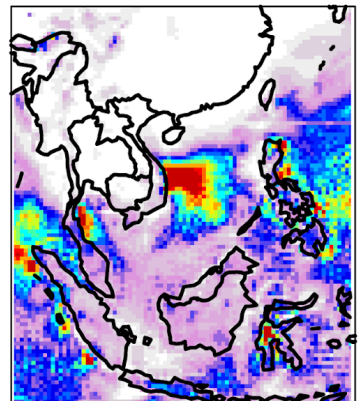

August

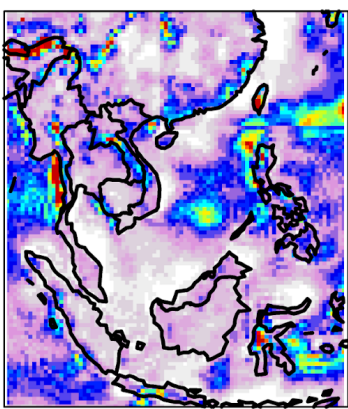

December

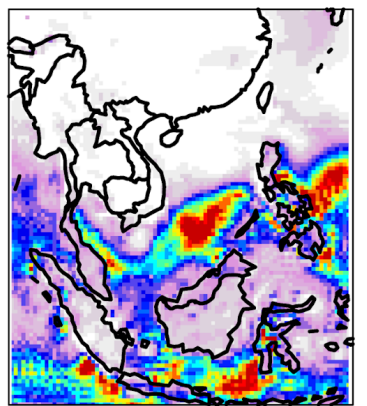

Figure S1. Monthly precipitation amount over Southeast Asia simulated by the Weather Research and Forecasting (WRF) model. 

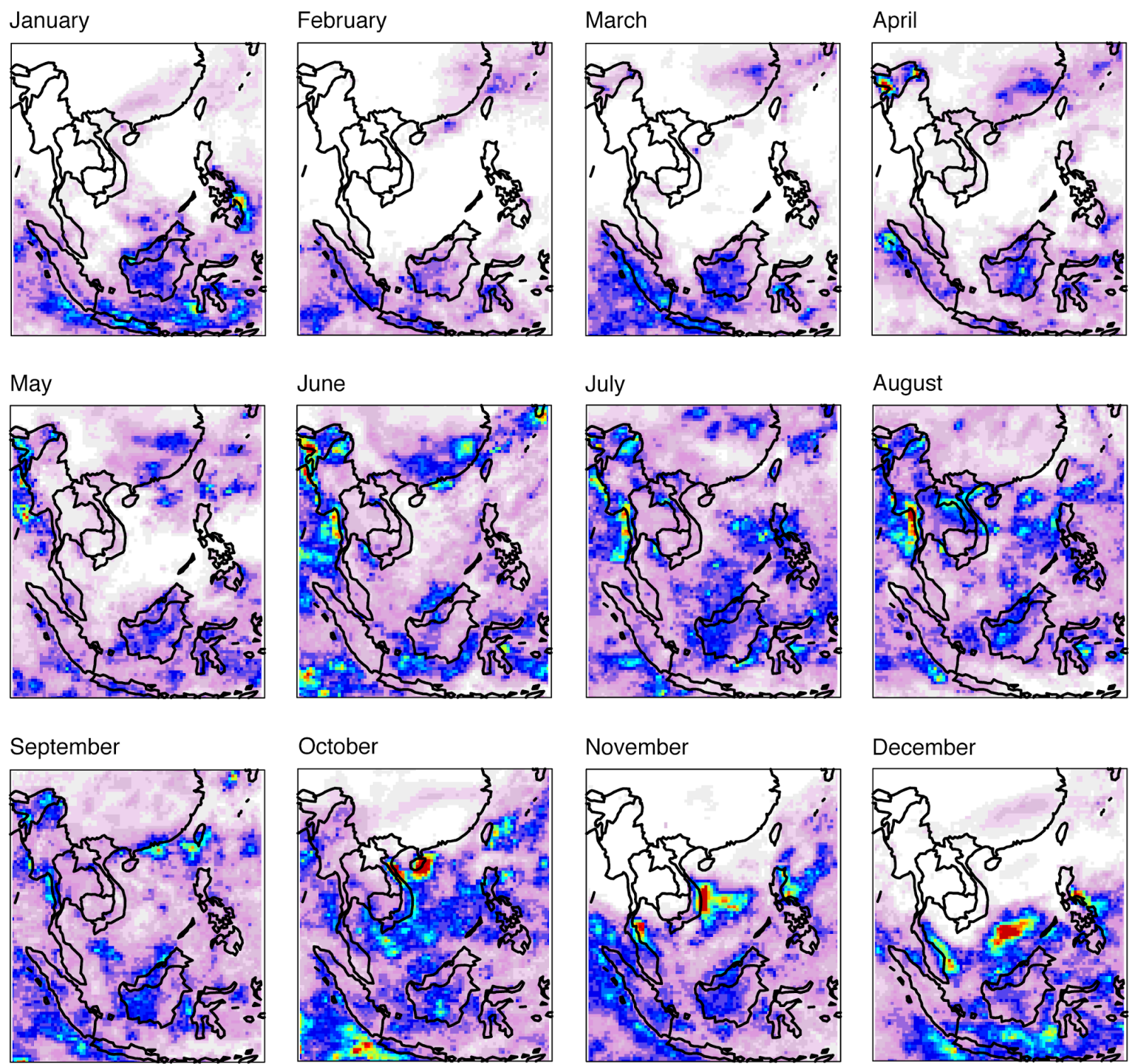

\section{October}

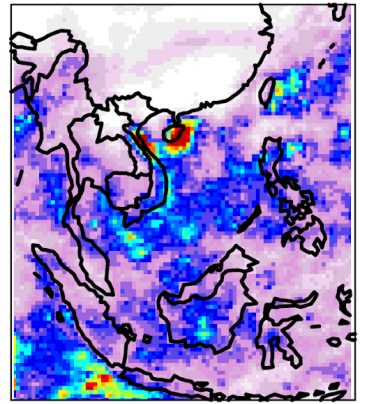

November

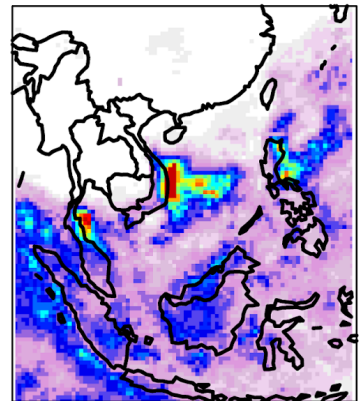

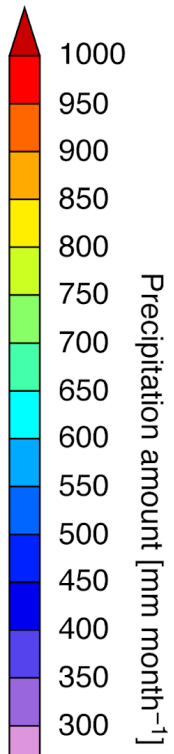

December

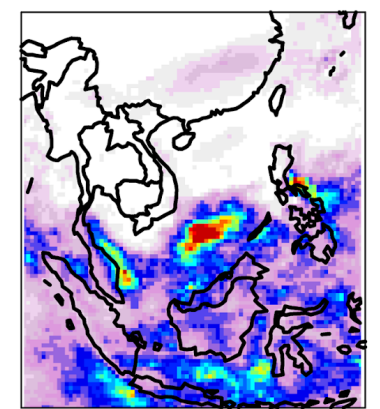

Figure S2. Monthly precipitation amount over Southeast Asia from Tropical Rainfall Measuring Mission (TRMM) satellite measurements. 

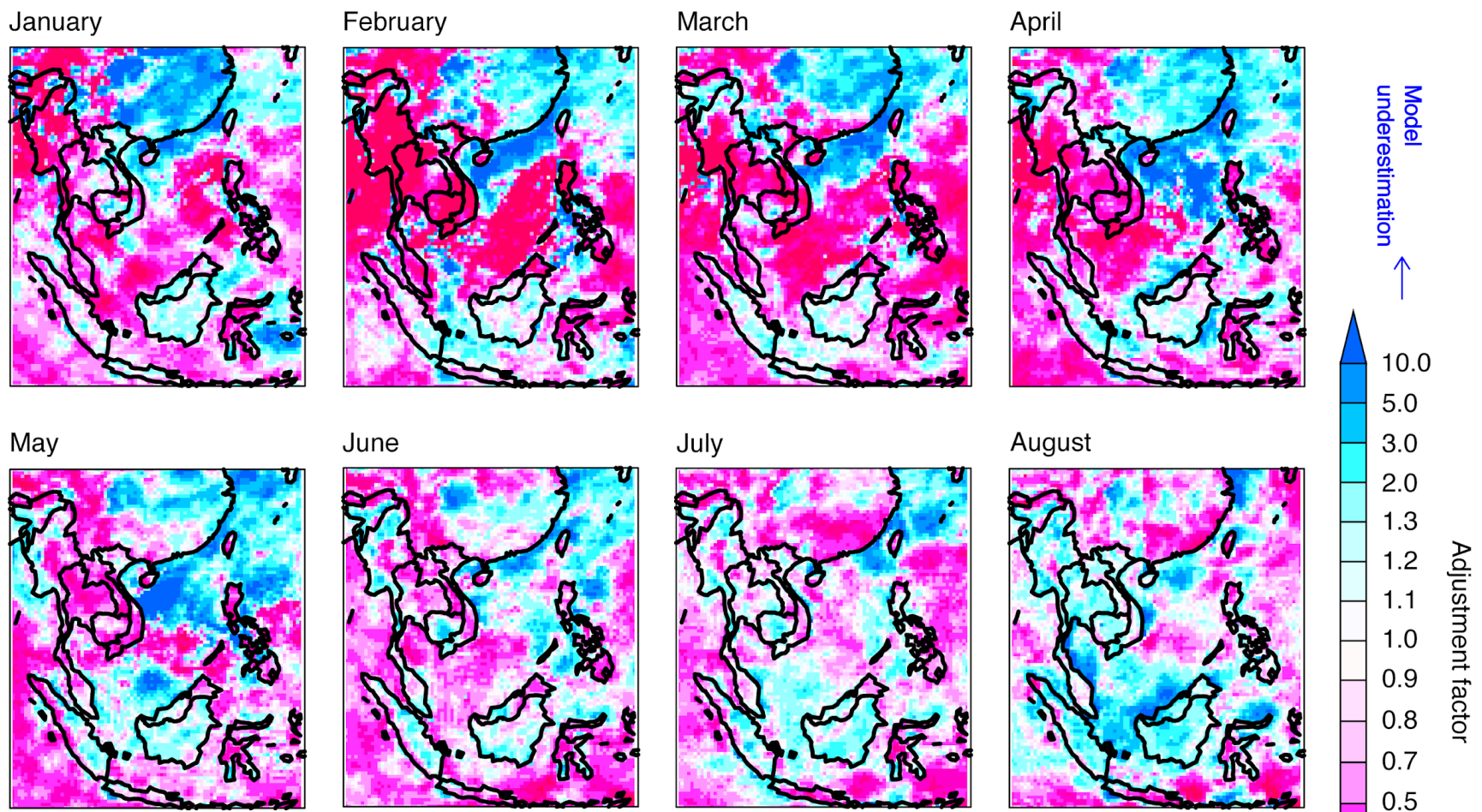

September

October

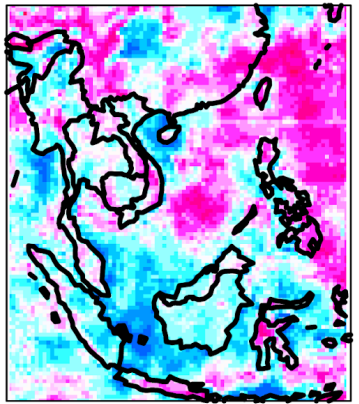

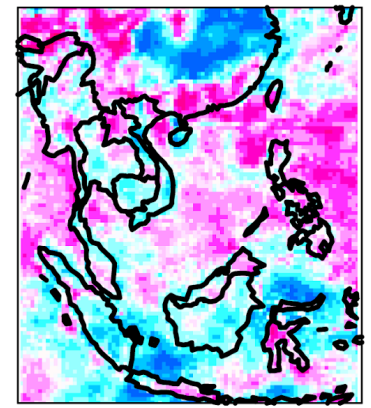

November

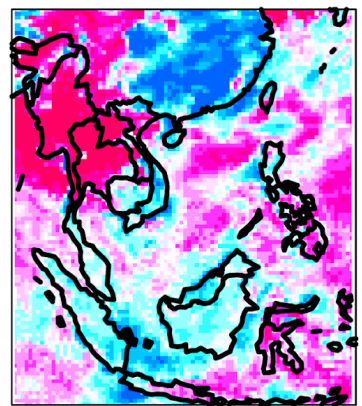

December

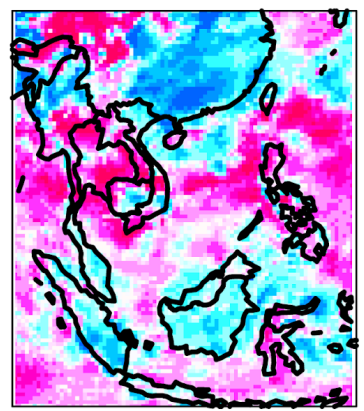

0.5

0.3

0.2

0.1

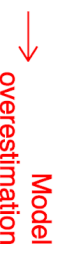

Figure S3. Adjustment factor (satellite measurements divided by modeled value) for precipitation over Southeast Asia in each month. 